\title{
Seizures and Epilepsy After Stroke: Epidemiology, Biomarkers and Management
}

\author{
Marian Galovic ${ }^{1,2,3}\left(\mathbb{D}^{2} \cdot\right.$ Carolina Ferreira-Atuesta $^{2,3,4} \cdot$ Laura Abraira $^{5,6} \cdot$ Nico Döhler $^{7} \cdot$ Lucia Sinka $^{1} \cdot$ Francesco Brigo $^{8}$. \\ Carla Bentes ${ }^{9} \cdot$ Johan Zelano ${ }^{10,11} \cdot$ Matthias J. Koepp ${ }^{2,3}$
}

Accepted: 23 January 2021 / Published online: 23 February 2021

(c) The Author(s) 2021

\begin{abstract}
Stroke is the leading cause of seizures and epilepsy in older adults. Patients who have larger and more severe strokes involving the cortex, are younger, and have acute symptomatic seizures and intracerebral haemorrhage are at highest risk of developing post-stroke epilepsy. Prognostic models, including the SeLECT and CAVE scores, help gauge the risk of epileptogenesis. Early electroencephalogram and blood-based biomarkers can provide information additional to the clinical risk factors of post-stroke epilepsy. The management of acute versus remote symptomatic seizures after stroke is markedly different. The choice of an ideal antiseizure medication should not only rely on efficacy but also consider adverse effects, altered pharmacodynamics in older adults, and the influence on the underlying vascular co-morbidity. Drug-drug interactions, particularly those between antiseizure medications and anticoagulants or antiplatelets, also influence treatment decisions. In this review, we describe the epidemiology, risk factors, biomarkers, and management of seizures after an ischaemic or haemorrhagic stroke. We discuss the special considerations required for the treatment of post-stroke epilepsy due to the age, co-morbidities, co-medication, and vulnerability of stroke survivors.
\end{abstract}

Marian Galovic

marian.galovic@usz.ch

1 Department of Neurology, Clinical Neuroscience Center, University Hospital and University of Zurich, Frauenklinikstrasse 26, 8091 Zurich, Switzerland

2 Department of Clinical and Experimental Epilepsy, UCL Queen Square Institute of Neurology, London, UK

3 Chalfont Centre for Epilepsy, Chalfont St Peter, UK

4 Department of Neurology, Icahn School of Medicine at Mount Sinai, New York, USA

5 Epilepsy Unit, Department of Neurology, Vall d'Hebron Hospital Universitari, Barcelona, Spain

6 Universitat Autonoma de Barcelona, Bellaterra, Spain
Specialist Clinic for Neurorehabilitation, Kliniken Beelitz, Beelitz-Heilstätten, Germany

8 Division of Neurology, "Franz Tappeiner" Hospital, Merano, Italy

9 Department of Neurosciences and Mental Health (Neurology), Hospital de Santa Maria-CHLN, Lisboa, Portugal

10 Department of Clinical Neuroscience, Institute of Neuroscience and Physiology, Sahlgrenska Academy at University of Gothenburg, Gothenburg, Sweden

11 Department of Neurology, Sahlgrenska University Hospital, Gothenburg, Sweden 


\section{Key Points}

Clinical characteristics, imaging and electroencephalogram findings, and blood biomarkers may be integrated into prognostic models to gauge the risk of seizures following stroke.

The treatment of post-stroke epilepsy needs to be adapted to the individual, considering changes in pharmacodynamics due to older age, co-morbidities, and co-medications in stroke survivors.

Because older adults may be more prone to adverse effects from antiseizure medications, their reduction or complete withdrawal should be considered in seizurefree individuals.

\section{Introduction}

Stroke is the most common cause of seizures and epilepsy in older adults [1]. Post-stroke epilepsy eventually develops in about $6 \%$ of the 3-6 million people who have a stroke annually [2]. Seizures shortly after stroke can lead to increased metabolic stress and cell death, causing an increase in infarct size, mortality, and negative functional outcomes [3-5]. Recurrent seizures may lead to injuries, affect cognition and the ability to work or operate vehicles, and decrease the quality of life [6,7]. Older age, comorbidities, co-medications, and the general vulnerability of stroke survivors must be taken into account in decisions about when and how to treat post-stroke seizures. Here, we review the epidemiology, risk factors, biomarkers, and management of seizures after an ischaemic or haemorrhagic stroke.

Seizures after stroke are dichotomized into acute and remote symptomatic. Acute symptomatic seizures (also called 'early' seizures) occur within 7 days after an infarct [8] and are considered to be provoked by the toxic or metabolic effects of stroke. Remote symptomatic seizures (also called 'late' seizures) are unprovoked seizures that occur more than 1 week after stroke. The risk of subsequent unprovoked seizures after acute symptomatic seizures is about $30 \%$, so acute symptomatic seizures are not considered epilepsy as such because of this low risk of recurrence $[9,10]$. In contrast, a single remote symptomatic seizure after stroke carries a $>60 \%$ risk of subsequent unprovoked seizures and is sufficient for the diagnosis of epilepsy in this context.

\section{Epidemiology}

The majority of strokes occur in adults aged $>45$ years [11]. Up to $90 \%$ of strokes are ischaemic, the remainder being haemorrhagic. Stroke is the most common identifiable aetiology of acquired epilepsy in high-income countries [12].

Risk estimates of epilepsy after stroke have been extensively studied and vary with study methodology. In the general population, prospective follow-ups of large cohorts or register-based studies provide the most representative estimates. An incidence of post-stroke epilepsy of $6.4 \%$ was found both in a population-based study in London (UK) and in a nationwide registry in Sweden [13, 14]. In single-centre studies from academic hospitals, which typically treat younger patients and more severe cases of stroke, the cumulative incidence of subsequent epilepsy can be above $15 \%$, particularly in severely affected patients who receive thrombolysis $[15,16]$. The incidence of epilepsy after haemorrhagic stroke is just above $12 \%$. The risk of post-stroke epilepsy is greatest within the first years after stroke. In those who develop epilepsy, almost $85 \%$ experience the first remote symptomatic seizure within the first 2 years after stroke [17].

The epidemiology of acute symptomatic seizures is less well defined. Acute seizures were observed in 1-4\% of patients with ischaemic stroke but in up to $16 \%$ of those with intracerebral haemorrhage [18, 19].

\section{Risk Factors, Imaging, and Prognostic Models}

Consistently identified risk factors of post-stroke epilepsy include acute symptomatic seizures, cortical involvement, stroke severity and aetiology, young age, and stroke type (haemorrhagic vs. ischaemic) [13, 16, 19]. Similarly, a meta-analysis found acute symptomatic seizures, cortical involvement, and haemorrhage to increase the risk of epilepsy after stroke.

The evidence for co-morbidities influencing the risk of seizures after stroke is less consistent. Some results support an increased risk of vascular epilepsy in those with diabetes, dyslipidemic, hypertension, peripheral infections, depression, or dementia [20].

The relationship between reperfusion therapies after acute ischaemic stroke and acute and remote symptomatic seizures is currently unclear [21]. Several studies suggested a higher risk of seizures in those receiving reperfusion treatment [22, 23], whereas others did not find an association [24, 25]. There is a potential of confounding 
by treatment selection in these studies, because those with more severe strokes due to large vessel occlusion are more likely to receive reperfusion treatment and have a higher risk of seizures.

Little is known on imaging biomarkers of epileptogenesis, i.e. the development of epilepsy, after stroke [26]. No specific technique has so far proven helpful in visualizing epileptogenesis in humans. Some clues on the risk of poststroke epilepsy can be obtained from magnetic resonance imaging or computed tomography (CT) scans:

- Involvement of the cortex is highly associated with later seizures.

- Subcortical stroke does not increase the risk of poststroke epilepsy [27].

- Seizures are most common if the infarct or bleeding affects the anterior circulation [28] and, more specifically, the medial cerebral artery territory [29].
- Seizures are uncommon if the stroke affects only infratentorial structures.

- Larger lesions are more likely to cause seizures [30]: a lesion size $\geq 70 \mathrm{ml}$ increases the odds of seizures by fourfold [31].

Many of these risk factors are routinely available and can be combined to predict an individual's overall risk of developing epilepsy after stroke. A prognostic model, termed SeLECT (Fig. 1), has been shown to accurately and reliably predict the risk of post-stroke epilepsy after ischaemic stroke [19]. It involves five parameters: Severity of stroke, Large-artery atherosclerotic aetiology, Early seizures, Cortical involvement, and Territory of middle cerebral artery involvement. The highest SeLECT score (9 points) indicates a more than $80 \%$ risk of epilepsy within 5 years after stroke (Fig. 1). The model is available as the 'SeLECT score' app on the Apple AppStore and Google Play Store. a Calculation of SeLECT score

\begin{tabular}{ll} 
& SeLECT score (points) \\
\hline (Se) Severity of stroke & \\
\hline NIHSS $\leq 3$ & 0 \\
NIHSS 4-10 & 1 \\
NIHSS $\geq 11$ & 2 \\
(L) Large-artery atherosclerosis & \\
\hline No & 0 \\
Yes & 1 \\
(E) Early seizure ( $\leq 7$ days) & \\
No & 0 \\
Yes & 3 \\
(C) Cortical involvement & \\
No & 0 \\
Yes & 2 \\
(T) Territory of MCA & \\
No & 0 \\
Yes & 1 \\
\hline
\end{tabular}

\section{b Risk of remote symptomatic seizures}
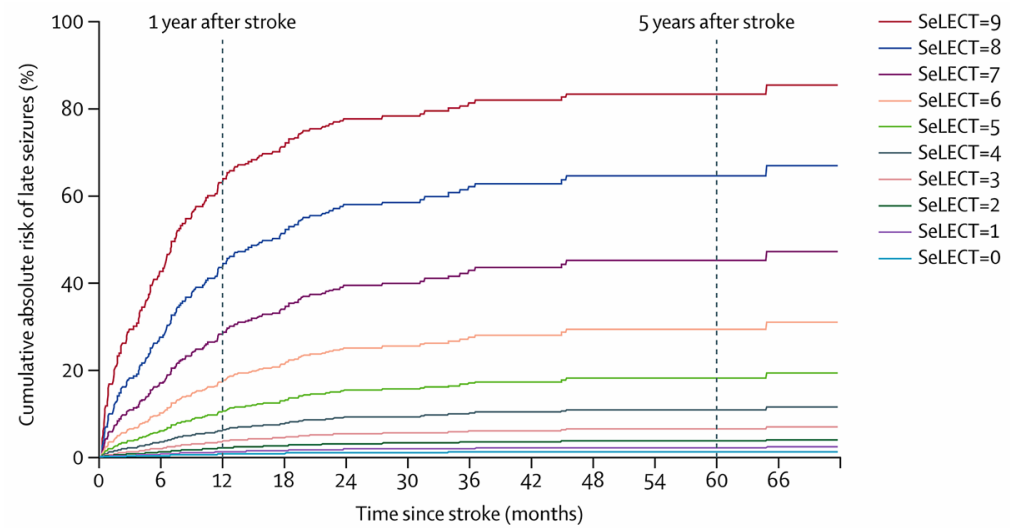

c Risk of remote symptomatic seizures after 1 year

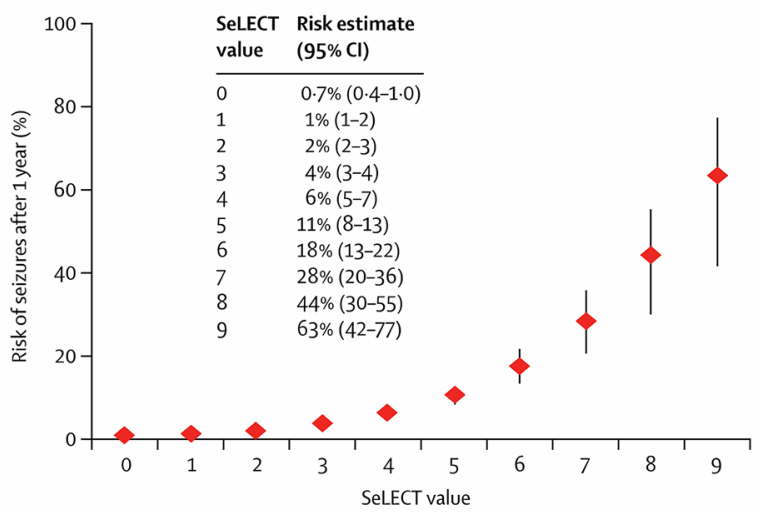

Fig. 1 Prediction of remote symptomatic seizures after ischaemic stroke using the SeLECT score. a Calculation of the SeLECT score; b Kaplan-Meier estimate curves of the risk of remote symptomatic d Risk of remote symptomatic seizures after 5 years

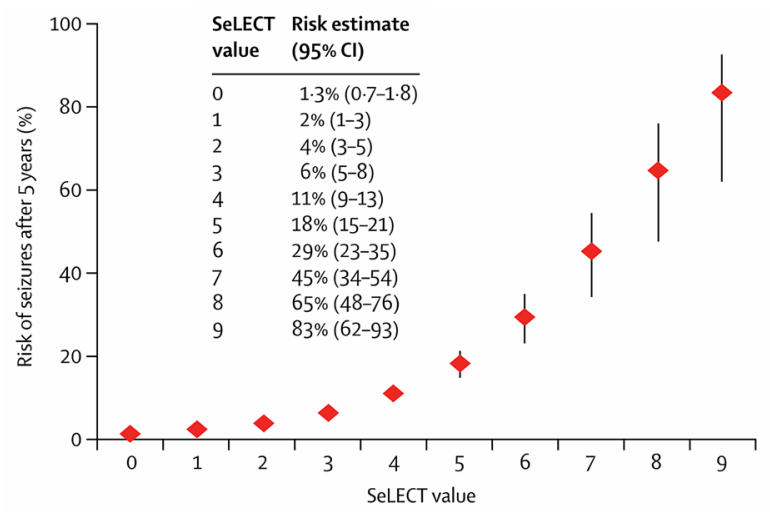

seizures according to different SeLECT values. The risk of remote symptomatic seizures after $\mathbf{c} 1$ year and $\mathbf{d} 5$ years. Reproduced from Galovic et al. [19] with permission 
Fig. 2 Prediction of remote symptomatic seizures after intracerebral haemorrhage using the CAVE score. a Calculation of the CAVE score; $\mathbf{b}$ risk of remote symptomatic seizures according to CAVE score during follow-up in the derivation and validation cohorts. For details see Sect. 3

\section{a Calculation of CAVE score $\quad$ b Risk of remote symptomatic seizures}

\begin{tabular}{lc}
\hline & Points \\
\hline Cortical involvement & \\
No & 0 \\
Yes & 1 \\
\hline Age & \\
$\geq 65$ years & 0 \\
$<65$ years & 1 \\
\hline Haemorrhage volume & \\
$\leq 10 \mathrm{~mL}$ & 0 \\
$>10 \mathrm{~mL}$ & 1 \\
\hline Acute symptomatic seizure \\
No & 0 \\
Yes & 1 \\
\hline
\end{tabular}

\begin{tabular}{lcc}
\hline \multirow{2}{*}{ CAVE score } & \multicolumn{2}{c}{ Seizure risk } \\
\cline { 2 - 3 } & Derivation & Validation \\
\hline 0 points & $0.6 \%$ & $3.1 \%$ \\
1 point & $3.6 \%$ & $5.0 \%$ \\
2 points & $9.8 \%$ & $15.8 \%$ \\
3 points & $34.8 \%$ & $13.5 \%$ \\
4 points & $46.2 \%$ & $37.5 \%$ \\
\hline
\end{tabular}

The CAVE score (Fig. 2) has been developed to gauge seizure risk after intracerebral haemorrhage and includes the factors Cortical location, younger Age, large hematoma Volume, and acute symptomatic sEizure [32]. The highest CAVE score (4 points) indicates a $46 \%$ risk of later seizures.

These scores are helpful in stratifying stroke survivors into low- and high-risk categories for the development of post-stroke epilepsy and to guide targeted follow-up. No treatment has so far proven beneficial for primary prevention of post-stroke epilepsy. Although these scores are not an instrument to guide primary preventive treatment, they may be used as recruitment tools for prospective studies of antiepileptogenic drugs.

In animal models of acquired epilepsy, a number of medications in clinical use for diverse indications have been reported to have an antiepileptogenic effect [33], including the antiseizure medications (ASMs) levetiracetam, brivaracetam, eslicarbazepine, topiramate, gabapentin, pregabalin, and vigabatrin. With the exception of levetiracetam for post-traumatic epilepsy, none of these medications have been studied systematically with the view of translation into clinical studies. This has contributed to the fact that almost none of the preclinical projects have led to clinical translation [34]. One main reason for the lack of anti-epileptogenesis trials is the relatively low (6\%) risk of post-stroke epilepsy in unselected stroke cohorts, which would require large numbers of patients $(N=1500)$ to show a moderate treatment effect (50\% reduction) during a reasonable observation period (18-24 months) following stroke. Tools such as the SeLECT score are required to provide an enriched population with at least a $20 \%$ risk of remote seizures following stroke to allow for an antiepileptogenesis trial to be feasible $(N=400)$.

\section{Electroencephalogram After Stroke}

The electroencephalogram (EEG) has a high temporal resolution, is important for the evaluation of brain function in real time, and is the gold standard for identifying different epileptogenesis and ictogenesis biomarkers [35, 36]. A systematic review and meta-analysis [37] found ictal and interictal epileptiform activity on EEG after stroke in 7\% (95\% confidence interval [CI] 3-12) and 8\% (95\% CI 4-13) of patients, respectively. These values may be even higher if long-term EEG monitoring is installed.

In an intensive care unit environment, seizures are frequently 'nonconvulsive' and may not be detected by clinical observation. EEG monitoring in this setting is essential for the diagnosis and treatment of seizures and status epilepticus [38-40]. Among patients with acute stroke receiving EEG monitoring, epileptic activity can be detected in $17 \%$ of cases [41]. In ischaemic stroke, $11 \%$ had seizures [42, 43], $9 \%$ had exclusively nonconvulsive seizures, and $7 \%$ fulfilled criteria for nonconvulsive status epilepticus [44]. Nonconvulsive status epilepticus is associated with poor outcomes and increased mortality [45]. A prospective study found nonconvulsive status epilepticus in $4 \%$ of patients with acute ischaemic stroke [46]. Clinicians did not suspect ongoing epileptic activity in $40 \%$ of the cases with nonconvulsive status epilepticus on EEG. Thus, prolonged EEG monitoring may help detect status epilepticus even in patients without typical clinical signs of ongoing seizures.

Limited data exist on the role of EEG in a stroke unit setting. More than one-fifth of patients with seizures in a stroke unit had exclusively electrographic seizures [47]. A short-duration EEG identified $22.7 \%$ of acute symptomatic seizures in patients with an anterior circulation ischaemic stroke that were exclusively electrographic and therefore 
could not otherwise be recognized. Follow-up EEG may also help identify epilepsia partialis continua, which was observed in $1.7 \%$ of patients 1 year after the stroke [48].

The role of an early EEG in the prediction of post-stroke epilepsy is a pertinent clinical question but remains poorly explored. One prospective study [49] established early poststroke visual EEG features as independent predictors of epilepsy 1 year after stroke. The main risk factor on EEG was the early presence of interictal epileptiform activity (Fig. 3). The authors also proposed that the presence of periodic discharges in an early EEG after stroke and the presence of islands of preserved cortex within the infarct in the CT scan could help to identify patients requiring a more extensive or repetitive neurophysiological assessment in the stroke unit.

Early EEG may also help in the differential diagnosis between an epileptic seizure and a transient ischaemic attack [50], particularly if imaging does not show an infarct. An EEG may support the clinical diagnosis of seizure in less than half of suspected cases [51]. Patients with seizures may show specific or nonspecific EEG abnormalities, whereas $90 \%$ of patients with transient ischaemic attack had a normal EEG [52].

\section{Blood and Genetic Biomarkers}

A biomarker is defined as an objectively measured characteristic of a normal or pathologic biologic process [35]. Biomarkers of epileptogenesis may help predict the development of epilepsy following stroke.

Stroke-induced acute neuronal damage (hypoxia, metabolic dysfunction, global hypoperfusion, glutamate excitotoxicity, ion channel dysfunction, and blood-brain barrier [BBB] disruption) triggers a neuroinflammatory cascade. Consequently, multiple inflammatory mediators are released to repair the brain damage (damage-associated molecular patterns [DAMPs], cytokines, chemokines, complement, prostaglandins, and growth factors). When neuroinflammation persists over time, it can lead to neuronal and astroglial dysfunction and, consequently, altered synaptic transmission, hyperexcitability, neuronal loss, gliosis, and aberrant neurogenesis. Hence, all these mechanisms may be involved in the process of epileptogenesis $[33,53]$.

Some of the inflammatory molecules that are released after a brain insult have been evaluated as biomarkers in several stroke complications such as haemorrhagic transformation or pneumonia $[54,55]$. However, the role of these biomarkers in predicting post-stroke epilepsy is uncertain.

Acute symptomatic seizures (Fig. 4a) were associated with higher neural cell adhesion molecule (NCAM) and lower tumour necrosis factor receptor 1 (TNF-R1) levels in blood during the first $6 \mathrm{~h}$ after stroke onset [56]. NCAM may play a role in cellular adhesion and could point towards a higher synaptic plasticity in those with acute symptomatic seizures [57]. TNF-R1 is a proinflammatory cytokine that may exhibit a proconvulsive effect [58]. Lower levels of TNF-R1 in the blood of patients with acute symptomatic seizures could point towards increased binding of these receptors to $\mathrm{TNF} \alpha$ during stroke-induced neuroinflammation.

Post-stroke epilepsy (Fig. 4b) was associated with lower levels of S100 calcium-binding protein B (S100B) and heat shock $70 \mathrm{kDa}$ protein-8 (Hsc70) and higher levels of endostatin in the blood within $6 \mathrm{~h}$ of stroke onset [59]. The incidence of post-stroke epilepsy was $17 \%$ in cases with abnormalities in all three biomarkers, compared with less than $1 \%$ in those with no biomarker abnormalities. Another group observed increased levels of blood biomarkers of brain injury (S100B, neurofilament light, tau, glial fibrillary acidic protein, and neuron-specific enolase) in four subjects with post-stroke epilepsy [60]. S100B and Hsc70 belong to the DAMPs family of proteins that are released during the neuroinflammatory phase after a stroke [33]. Reduced levels of these proteins in those who later develop epilepsy may seem counter-intuitive, but S100B and Hsc70 are relevant for maintaining the functional integrity of the BBB, and reduced levels could aggravate BBB deficiency [61]. Endostatin is an inhibitor of angiogenesis and contributes to mediating neurogenesis and cellular proliferation [62]. A transient angiogenic response is observed after brain damage; thus, upregulation of endostatin could compromise cellular repair.

The fact that different biomarkers were observed in patients with acute and remote symptomatic seizures supports the notion that diverging mechanisms underlie these seizure types [12, 13]. In both cases, blood biomarkers may improve the prediction of patients who later experience acute or remote symptomatic seizures and could be valuable in addition to clinical or imaging factors.

Little is known about genetic factors and their role in post-stroke epilepsy. There may be a familial predisposition towards the development of vascular epilepsy, as suggested by the higher risk of post-stroke seizures in those with a first-degree relative with epilepsy, but the risk increase was small [63]. Three studies have assessed the contribution of genetic variants to epileptogenesis in patients with stroke [64-66]. Yang et al. [64] reported that allele A of the rs671 polymorphism in a gene encoding mitochondrial aldehyde dehydrogenase 2 was associated with post-stroke epilepsy and increased the plasma concentration of aldehyde dehydrogenase 2 substrate, 4-hydrozynomenal. Zhang and colleagues reported that a cluster of differentiation (CD)-40$1 \mathrm{C} / \mathrm{T}$ polymorphism might be associated with post-stroke epilepsy. They suggested increased plasma concentrations of sCD40L that are involved in the inflammatory response as a potential mechanism [65]. Fu et al. [66] reported that a polymorphism of TRPM6 (rs2274924) might be associated 
a

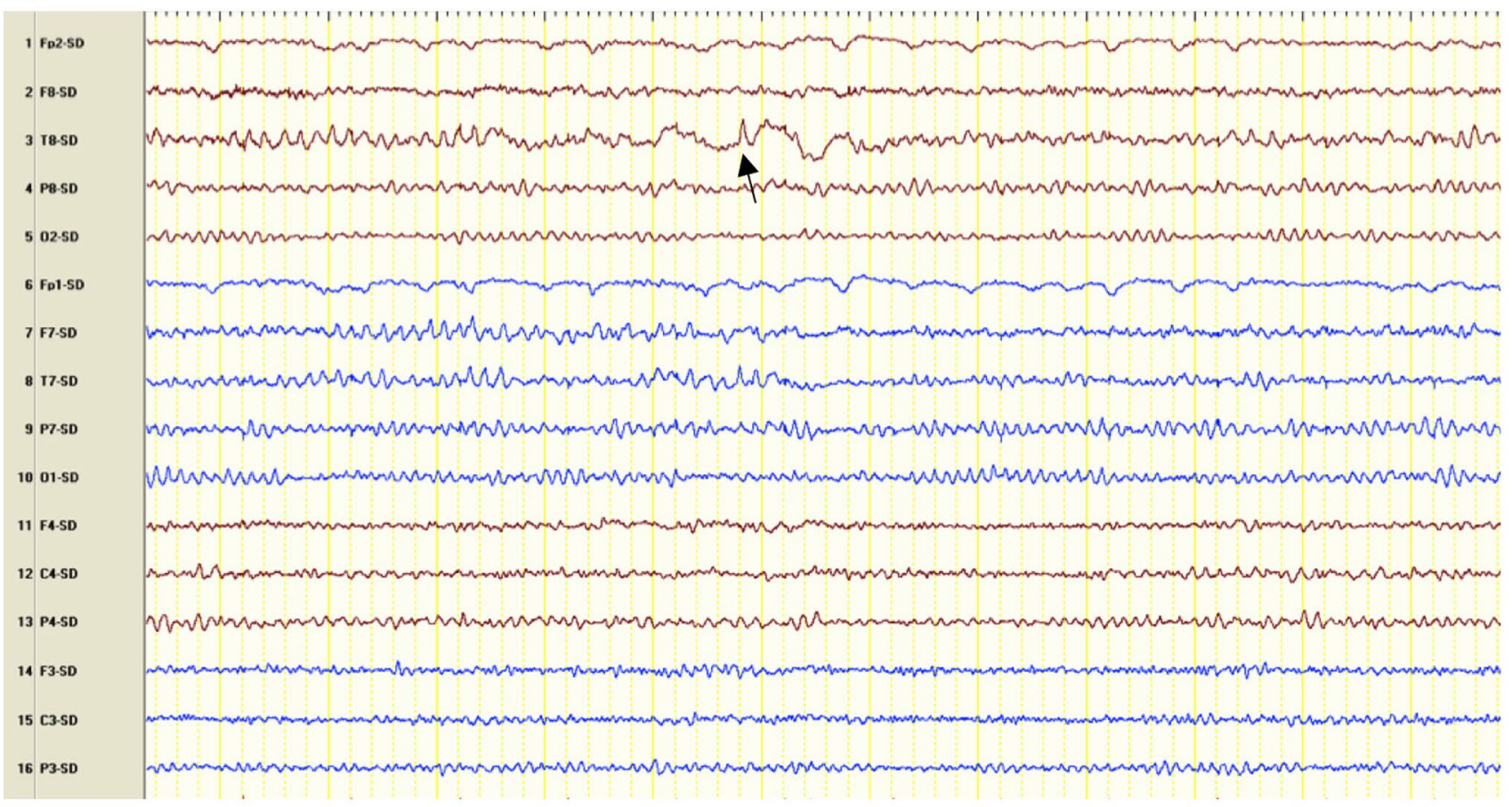

b

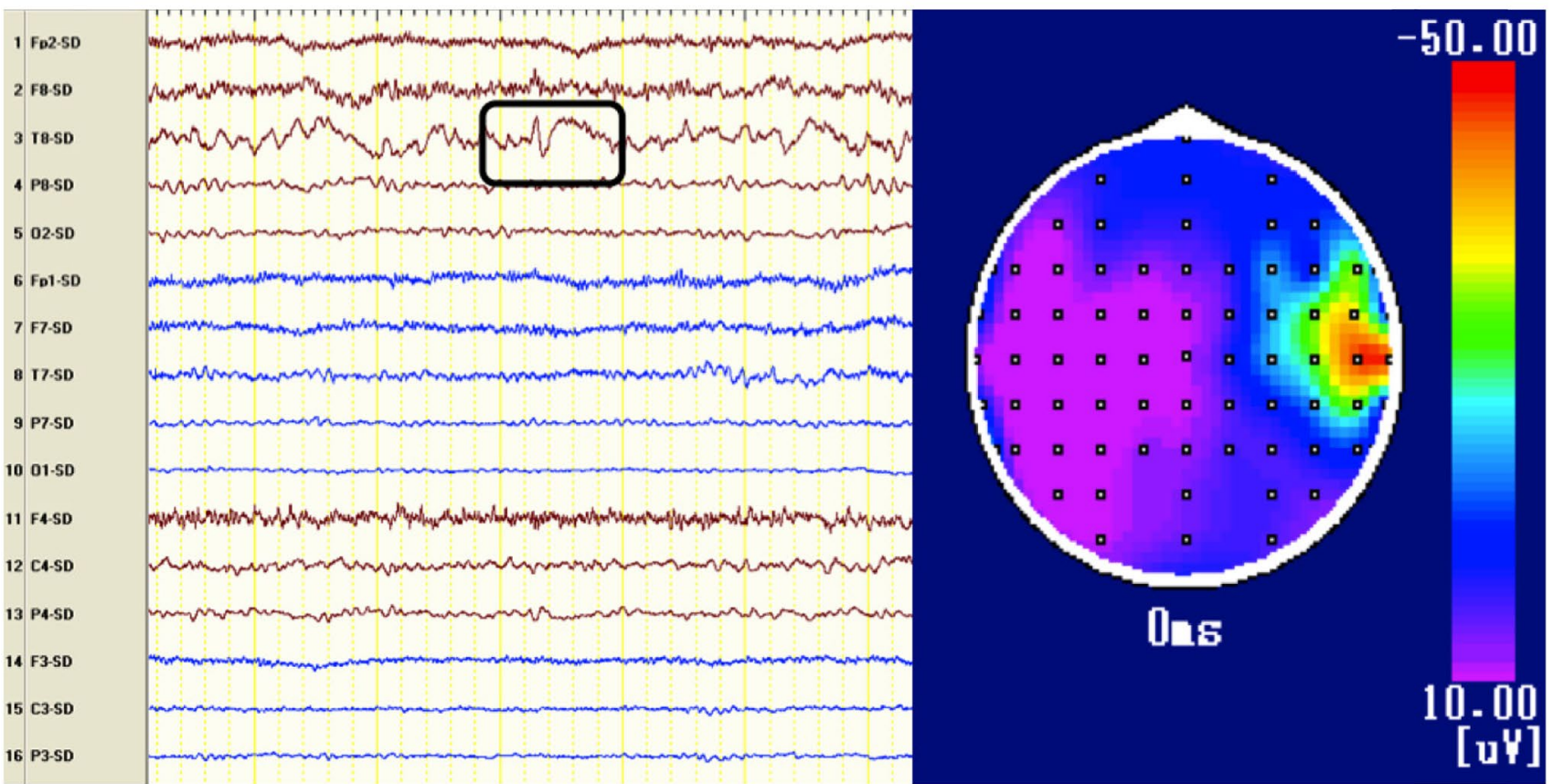

Fig. 3 Epileptiform electroencephalogram (EEG) findings in stroke survivors. a EEG in a patient with acute right-hemispheric stroke affecting the middle cerebral artery territory. Findings on source montage include focal slow wave activity over the right medial temporal region (T4 electrode) and epileptiform activity (a spike wave marked with a black arrow). b EEG and corresponding spike source localization on the right in a patient with acute right-hemispheric stroke affecting the middle cerebral artery territory. Findings on source montage include slow wave activity over the right anterior and medial temporal regions (F8 and T4 electrodes) and right temporal (T4 electrode) epileptiform activity (sharp wave marked with a black square) with corresponding source localization on the right 


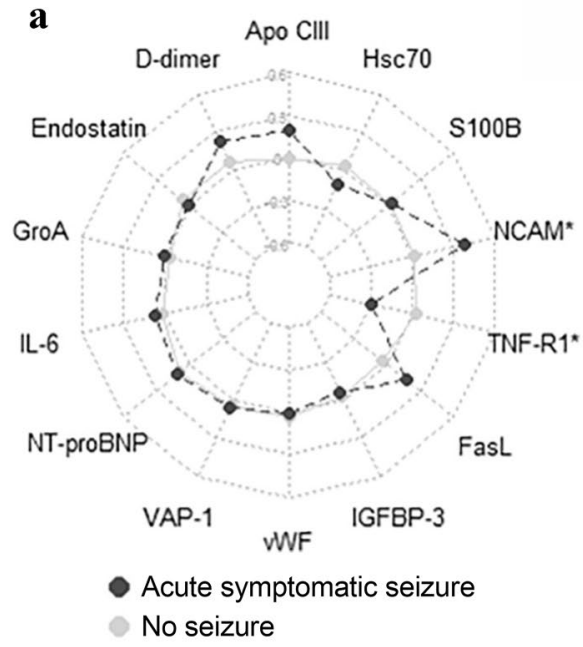

Fig. 4 Blood biomarkers of acute and remote symptomatic seizures after stroke. Radar charts of z-scores for biomarkers of a acute or $\mathbf{b}$ remote symptomatic seizures. ApoCIII apolipoprotein CIII, FasL Fas ligand, GroA growth-related oncogene $\alpha, H s c 70$ heat shock $70 \mathrm{kDa}$ protein-8, IGFBP-3 insulin-like growth factor binding protein-3, $I L$ -

with susceptibility to epilepsy following ischaemic stroke. In addition, post-stroke epilepsy patients with this polymorphism had significantly decreased serum levels of $\mathrm{Mg}^{2+}$, indicating that TRPM6 polymorphism may also influence serum levels of $\mathrm{Mg}^{2+}$ in these patients [66].

\section{Management of Acute Symptomatic Seizures}

The temporal cut-off for acute ( $\leq 7$ days) versus remote $(>7$ days) symptomatic seizures after stroke has been set, hypothesizing fundamentally different aetiologic mechanisms. Early seizures are assumed to be caused by potentially transient processes in the acute phase after stroke, including hypoxia, cerebral perfusion shift, neuronal metabolic dysfunction, and excitotoxicity as well as BBB disruption [67]. Although they occur infrequently, they have been associated with elevated mortality $[10,68]$ and are a risk factor for the development of epilepsy $[19,69]$. Patients with acute symptomatic seizures after stroke have a 10 -year recurrence risk for unprovoked seizures of 33\% [9, 10]. Thus, acute symptomatic seizures alone are insufficient to diagnose epilepsy. In contrast, remote symptomatic seizures have a recurrence rate of $72 \%$ within 10 years; because of this high recurrence risk, a single remote unprovoked seizure qualifies as epilepsy [9].

Overall, the management of acute symptomatic seizures after stroke is much debated. Given the low recurrence risk of acute symptomatic seizures, the initiation of ASMs is usually not recommended. However, there is a discrepancy between guideline recommendations and common bedside

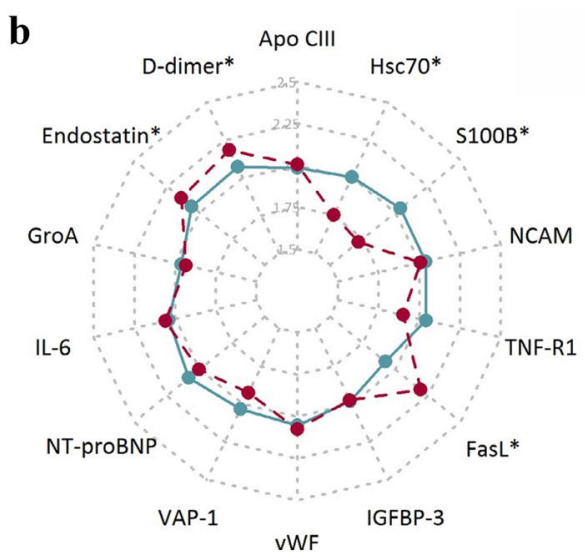

Remote symptomatic seizure

No seizure

6 interleukin 6, NCAM neural cell adhesion molecule, NT-proBNP $\mathrm{N}$-terminal Pro-B-type natriuretic peptide, $S 100 B$ S100 calcium-binding protein $\mathrm{B}, T N F$ tumour necrosis factor, $V A P-1$ vascular adhesion protein-1, $v W F$ von Willebrand factor. Reproduced from Abraira and colleagues $[56,59]$ with permission

practice. Off-label administration of ASM is frequently initiated after an acute symptomatic seizure. Such treatment is usually time limited and restricted to several weeks or months after the stroke. Many clinicians pursue such an approach aiming to avoid further seizures and prevent their potential negative impact on clinical outcomes [70]. Adequately powered controlled trials for the prevention or even treatment of acute symptomatic seizures are not available.

Despite the relatively low risk of recurrences after acute symptomatic seizures, such seizures may not be entirely benign. Ictal patterns and periodic discharges on EEG are associated with neurological deterioration after stroke [5]. Seizures and periodic discharges are associated with increased metabolic demand [71] and can lead to metabolic crisis [72]. Thus, treatment of early seizures or epileptic activity on EEG may be relevant in situations with reduced brain perfusion. These include ischaemic stroke with hemodynamically relevant stenosis, brain oedema, or vasospasms after subarachnoid haemorrhage. Other relevant conditions include recent surgery or trauma, where repeated acute symptomatic seizures could lead to worsening. In these situations, short-term treatment with ASM may be warranted. In most other cases, treatment of isolated acute symptomatic seizures is neither necessary nor recommended $[70,73]$.

Another aspect of early treatment is the potential to interfere with epileptogenesis. There is little evidence to support such primary preventive treatment. ASMs suppress seizures but do not have documented effects on antiepileptogenesis. Currently available prognostic models and biomarkers do not allow prediction of the later development of poststroke epilepsy with sufficient certainty to warrant primary 
preventive treatment. Although experimental findings for antiepileptogenic treatment have been promising [74], they have not been replicated in humans [73].

Antiepileptogenic treatment trials mostly focused on primary prevention of epilepsy after traumatic brain injury or brain tumours, and the results were negative [75]. One randomized controlled trial evaluating the primary prevention of post-stroke epilepsy with levetiracetam compared with placebo did not include a sufficient number of participants to allow any definitive conclusions [76].

Some recent interest surrounded the use of eslicarbazepine acetate [77] and sodium selenate [78] as potentially antiepileptogenic compounds. Several observational studies found a reduced incidence of acute symptomatic seizures in patients who were prescribed statins $[17,79]$. One study also found a lower risk of epilepsy within 1 year after stroke in patients started on simvastatin [80]. Such observational analyses are limited by potential confounding or treatment selection bias, and the results should be interpreted with caution. These observations will need to be replicated in larger prospective controlled trials.

\section{Management of Post-Stroke Epilepsy}

The use of ASMs aims to reduce the risk of seizure recurrence. Typically, they are reserved for the treatment of unprovoked remote symptomatic seizures, which, unlike acute symptomatic seizures, have a high risk of recurrence. However, the choice of starting an ASM treatment after a single unprovoked post-stroke seizure should always rely on an overall assessment of the patient. In some cases, there may be reasons to justify deferral of treatment or no treatment at all, for instance, in patients under constant supervision, lack of ambulation with low risk of seizure-related injury, and very mild seizures [14].

If prophylactic treatment after a first unprovoked seizure is appropriate or necessary, the selection of ASM should rely on the best evidence available in the literature and consider some clinical and pharmacological issues [73]. A pragmatic approach is to 'start slow and aim low'. This will reduce the intensity and risk of adverse effects and establish a therapeutic response at the lowest viable dose [81]. Many patients with post-stroke epilepsy respond well to even lowdose treatment [82]. Monotherapy is usually preferred to polytherapy. Dose finding needs to consider kidney and liver function and body weight. The use of soluble medications may be helpful in stroke survivors with dysphagia. Most studies evaluated ASMs in ischaemic stroke, and only little data exist on ASM usage in primary haemorrhagic stroke. Nevertheless, the principles of treatment in ischaemic and haemorrhagic stroke are similar, and treatment selection is mainly guided by the patients' age, co-morbidities, and co-medications.

The evidence supporting the use of specific ASMs is limited and of low quality $[83,84]$. Two randomised open-label studies compared controlled-release carbamazepine and lamotrigine [85] or levetiracetam [86]. These studies were conducted in a small number of patients so were underpowered to reveal a statistically significant and clinically relevant difference between the drugs in 12-month seizure-freedom rates (44 and $85 \%$ for controlled-release carbamazepine; 72 and $94 \%$ for lamotrigine and levetiracetam). However, in both studies, controlled-release carbamazepine was less well-tolerated than lamotrigine and levetiracetam, a finding consistent with other studies conducted in older adults with epilepsy of various aetiologies. Both these studies were open label and of low quality with an unclear or high risk of selection bias, allocation concealment, performance bias, and detection bias [84]. A recent systematic review with network meta-analysis of these two trials showed no difference between levetiracetam and lamotrigine for seizure freedom (odds ratio [OR] 0.86; 95\% confidence interval [CI] $0.15-4.89)$, potentially due to a lack of statistical power to detect a difference [84]. However, it showed a greater occurrence of adverse events for levetiracetam than lamotrigine (OR 6.87; 95\% CI 1.15-41.1) [84].

Uncontrolled trials showing the efficacy and tolerability of individual drugs such as eslicarbazepine acetate [87], gabapentin [88], levetiracetam [89, 90], valproic acid, and other newer ASMs [91] are also sparse. However, the validity of these studies is limited by bias, placebo effect, regression to the mean, and other confounding factors.

Given the lack of high-quality evidence to support the use of specific ASM for the treatment of post-stroke seizures, drug selection should rely mostly on the results of randomised controlled trials conducted in older adults with focal epilepsy of various aetiologies. These studies have evaluated the efficacy and tolerability of gabapentin [92], lacosamide [93], lamotrigine [92, 94-96], levetiracetam [97], and valproic acid [97] tested against immediate- or controlled-release carbamazepine. They consistently showed that newer ASMs had a better tolerability profile than carbamazepine, without significant differences in seizure control and sometimes with higher retention rates $[94,96$, 97]. Recently, a network meta-analysis estimated the comparative efficacy and safety of ASMs in older adults with new-onset epilepsy [98]. No significant difference in efficacy was found across treatments, although lacosamide, lamotrigine, and levetiracetam had the highest probability of ranking best for achieving seizure freedom, whereas immediate- and controlled-release carbamazepine showed a less favourable tolerability profile, with higher withdrawal rates than levetiracetam and valproic acid [98]. However, results from trials conducted in older adults, particularly 
those on efficacy, should be generalised with caution to the population of patients with post-stroke epilepsy because of the differences in the proportion of patients with post-stroke epilepsy included in each trial. A recent exploratory post hoc analysis of comparative trials between lacosamide and controlled-release carbamazepine showed that lacosamide was generally well-tolerated in patients with post-stroke epilepsy [99]. More patients on lacosamide than controlled-release carbamazepine completed 6 months (82 vs. 59\%) and 12 months (67 vs. $50 \%$ ) of treatment without seizure at the last evaluated dose, whereas no formal statistical analysis was possible [99]. Lacosamide was also reported as a safe potential treatment of nonconvulsive status epilepticus in older adults, but prospective comparative trials will be necessary to determine its efficacy [100].

\section{Adverse Effects and Interactions}

Drug selection in older adults should not only rely on drug efficacy but also individually consider appropriate dosing in the light of changing pharmacodynamics as well as the increased potential for adverse effects and interactions. By definition, all patients with post-stroke seizures have vascular co-morbidity, take other drugs (e.g. antiplatelet agents or anticoagulants, statins, anti-hypertensive drugs, etc.), and are likely to be aged $\geq 65$ years and have residual neurological deficits [101]. Hence, the ideal ASM should have minimal or no detrimental effect on the underlying vascular disease, for instance, it should not affect surrogate markers associated with increased risk of cardio/cerebrovascular accidents (e.g. low-density cholesterol, lipoprotein, C-reactive protein, homocysteine, carotid artery intima-media thickness, etc.) $[102,103]$. Furthermore, it should have no relevant drug interactions, be effective, well-tolerated, and safe to administer in patients with renal or hepatic failure.

Accordingly, enzyme-inducing ASMs, such as carbamazepine, phenytoin, phenobarbital, and primidone, should be avoided whenever possible, as they can increase serum levels of lipids and other biochemical markers of vascular disease [101]. Furthermore, they can increase the hepatic metabolism of several co-medications, some of which (e.g. warfarin) are used in post-stroke patients. Recently, the European Heart Rhythm Association advised against the use of some ASMs in association with nonvitamin $\mathrm{K}$ antagonist oral anticoagulants [104] because of the potential risk of decreasing the anticoagulant effect by inducing P-glycoprotein (carbamazepine, levetiracetam, phenobarbital, phenytoin, and valproic acid) or cytochrome P450 3A4 activity (carbamazepine, oxcarbazepine, phenytoin, phenobarbital, and topiramate) [105]. However, these recommendations are based on the summary of product characteristics and expert opinions, as so far only sporadic case reports in humans exist $[105,106]$. Thus, further clinical studies are required to evaluate the clinical relevance of these drug interactions. Until then, caution should be taken when using certain ASMs with novel oral anticoagulants.

Pharmacodynamics may be altered in older adults. Renal function declines steadily with increasing age. Potential exists for reduced hepatic metabolism, protein binding, and enzyme induction. The effect of ageing on pharmacodynamics and changes in homeostatic mechanisms and neurotransmission can increase the risk of adverse effects in this population [107]. Older adults are more vulnerable to dose-related adverse effects, typically including drowsiness, fatigue, dizziness, blurry vision, impaired concentration or memory, and ataxia [108].

Cognitive decline is more common in older adults. The sedative and anticholinergic burden of ASMs, particularly those given as polytherapy, may aggravate cognition [109]. Negative impacts on cognition were particularly observed with 'older' ASMs, i.e. those developed before 1990, and were documented for phenobarbital, carbamazepine, phenytoin, and valproate [110]. The most prominent effects on cognition were seen with phenobarbital. Of the 'newer' ASMs, dosage-dependent cognitive impairment affecting verbal function is an adverse effect of topiramate, particularly in dosages higher than $75 \mathrm{mg} /$ day [111]. Other newer 'ASMs', such as gabapentin, lamotrigine, and levetiracetam, showed fewer adverse cognitive effects than carbamazepine $[112,113]$.

Psychiatric and behavioural adverse effects are particularly relevant in those with a history of psychiatric conditions, intractable seizures, secondarily generalized seizures, and absence seizures [114]. Levetiracetam (22\%) and zonisamide (10\%) were particularly likely to induce behavioural adverse effects. By contrast, carbamazepine, oxcarbazepine, gabapentin, lamotrigine, phenytoin, clobazam, and valproate were associated with better behavioural tolerability [115, 116]. Drug-drug interactions can also lead to a reduction of the plasma level of concurrent psychotropic medicines, resulting in a decline in the efficacy of antidepressant medication [117].

Bone health is a relevant issue in older adults. Enzymeinducing ASMs, such as phenobarbital, phenytoin, carbamazepine, and primidone, as well as the enzyme inhibitor valproate, may increase the risk of fractures. Enzyme induction can lead to accelerated metabolism of vitamin D and increased bone turnover [118-120]. In the case of valproate, its bone-depleting properties result from the interference with the function of osteoblasts [121]. The duration of the ASM therapy is an important factor for the decrease of bone density and the risk of fractures. Particular caution is required when using these ASMs in older women with a history of osteoporosis [122]. 
Hyponatraemia may commonly occur through pharmacodynamic interactions when carbamazepine, oxcarbazepine, or eslicarbazepine acetate are prescribed to patients treated with thiazides or other diuretic drugs [123, 124]. Oxcarbazepine has the highest propensity to cause hyponatraemia. Although hyponatraemia is commonly mild and develops slowly, it may aggravate seizure control and cause confusion or delirium in stroke survivors.

\section{Withdrawal of Antiseizure Medication}

Whether ASMs should be continued should be evaluated regularly. Withdrawal of medication is an option, particularly in those with long periods of seizure freedom or with very mild and infrequent seizures. Older adults may benefit from medication withdrawal as it may lessen adverse effects $[85,86]$ and prevent interactions with anticoagulants [125], lipid-lowering drugs [126, 127], or other drugs commonly prescribed for older adults [126, 128]. Furthermore, ASM therapy may negatively impact motor recovery [129] and bone density and increase healthcare costs [130], serum lipids, weight, and risk of cardiac arrhythmias [103]. Studies evaluating the risk of relapse after ASM withdrawal in people with lesional epilepsy have shown an increased risk for seizure relapses when withdrawal is attempted [131, 132].

The decision to begin withdrawal should be individualized based on a patient's clinical characteristics, co-medications, stroke type/morphology, co-morbidities, and personal preferences [73, 133]. Withdrawal after at least 2 years of seizure freedom may reduce the risk of relapses compared with earlier withdrawal [133, 134]. Given that more than two-thirds of individuals with post-stroke epilepsy achieve seizure freedom with one ASM, which is similar to other epilepsy aetiologies [135], some of these individuals may benefit from medication withdrawal.

A recent study developed a prognostic model to guide ASM withdrawal in seizure-free individuals, but the model is not specific to post-stroke epilepsy (Fig. 5) [133]. Factors that predict good outcomes include a shorter duration of epilepsy before remission, longer seizure-free interval before withdrawal, younger age of epilepsy onset, no history of febrile seizures, self-limited epilepsy syndromes, no developmental delay, and normal EEG before withdrawal [133]. This model does not include imaging abnormalities and has not been tested specifically in stroke survivors. The presence of a lesion after an ischaemic infarct or intracerebral haemorrhage likely reduces the chances of remaining seizure free after complete withdrawal of medication. Hence, ASM withdrawal in stroke survivors needs to be performed cautiously using an individually tailored approach because seizure relapses may increase mortality risk [136] and deteriorate neurological function [137]. Further studies are needed to address the risk of relapses after ASM withdrawal in poststroke epilepsy.

For individuals who started ASM therapy after acute symptomatic seizures, the general advice is to withdraw medication early after stroke because acute symptomatic seizures have a low risk of recurrence [14, 73, 138, 139]. The optimal 'observation period' before early ASM withdrawal
Fig. 5 Prediction of seizure recurrence after antiseizure medication withdrawal.

Nomogram to predict seizure recurrence risk after 2 or 5 years following antiseizure medication withdrawal. The nomogram is not specific to post-stroke epilepsy. Reproduced from Lamberink et al. [133] with permission

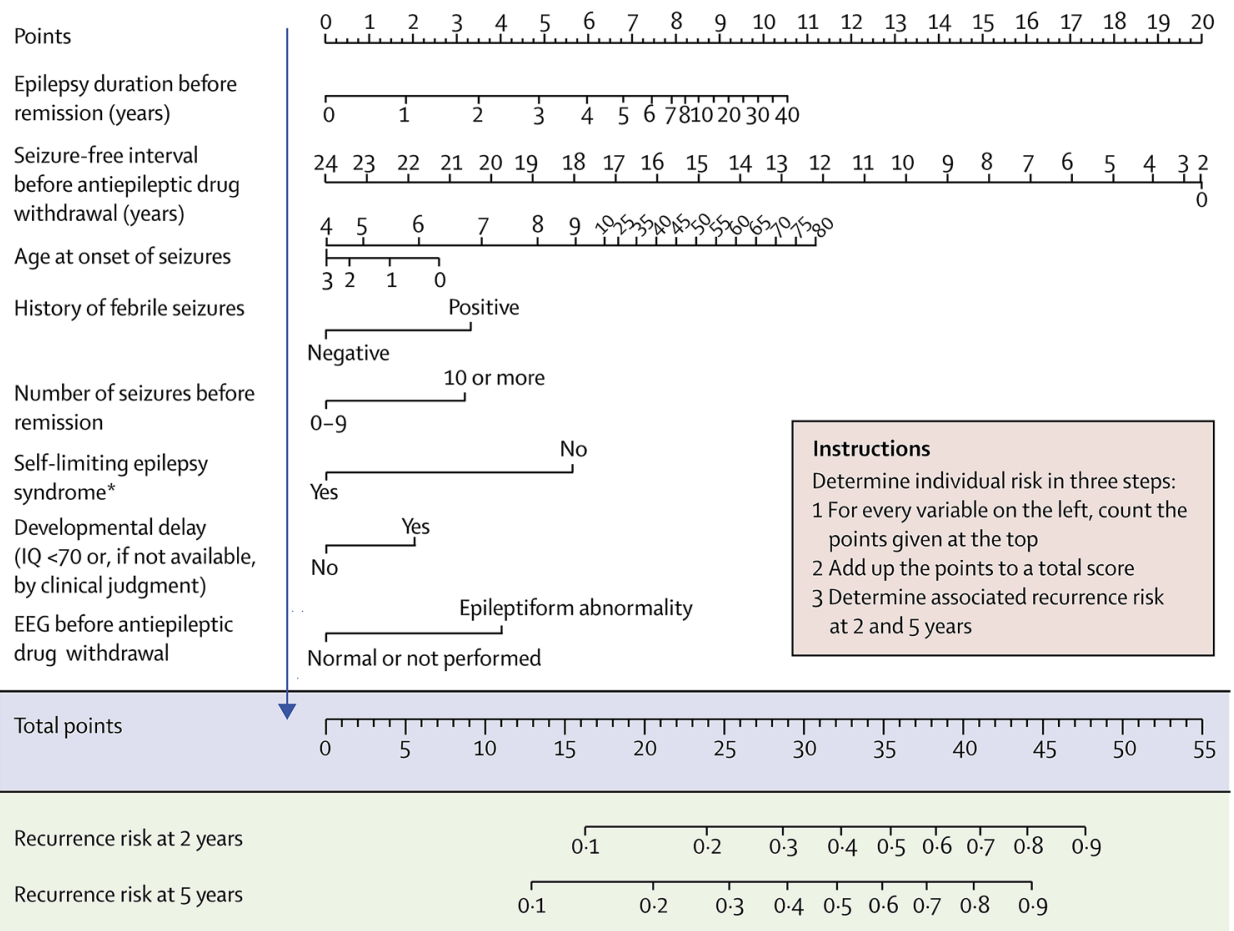


following acute symptomatic seizures is unknown, and clinical practice varies considerably. The authors of this article typically wait between 1 week and 3 months before initiating ASM withdrawal if ASMs were started after an acute symptomatic seizure. From a pathophysiological perspective, there is little reason to continue ASM treatment of acute symptomatic seizures beyond the acute phase unless the risk of unprovoked remote symptomatic seizures is considered very high. An observational study concluded that individuals receiving ASM immediately after the first post-stroke seizure had the same risk of relapse after withdrawal as those who did not receive ASM during the first 2 years [139]. In addition, none of the current available ASMs have been shown to prevent epileptogenesis or to improve the longterm prognosis [140] or mortality [141].

\section{Conclusions}

There are several avenues for future research on post-stroke epilepsy. Refinement and development of biomarkers of epileptogenesis will be important to predict which stroke survivors will later on have seizures. Such knowledge will also help recruitment for antiepileptogenic treatment trials. Stroke is an excellent model for such trials because the epileptogenic insult is usually well-defined and the latent period between an infarct and the development of seizures provides time for interventions.

The effect, tolerability, and interactions of ASMs will need to be studied specifically in the population of stroke survivors. The interaction of ASMs with non-vitamin K antagonist oral anticoagulants needs to be studied urgently. Lastly, better biomarkers of ongoing epileptic activity are needed to predict which patients may benefit from the withdrawal of ASM.

\section{Declarations}

Funding Open Access funding provided by Universität Zürich. No sources of funding were used to conduct this study or prepare this manuscript.

Conflict of interest Dr. Galovic has received fees and honoraria from Nestlé Health Science and Scope International. Dr. Zelano has been an investigator in clinical trials sponsored by Bial, SK Life science, UCB, and GW Pharma as an employee of Sahlgrenska University hospital (without personal compensation) and has received speaker honoraria at educational meetings organized by UCB and Eisai. Dr. Koepp has been an investigator in clinical trials sponsored by Bial, Novartis, Desitin, and UCB and has received honoraria from UCB, GSK, Novartis, Bial, Eisai, Desitin, and GE-Healthcare. Carolina Ferreira-Atuesta, Laura Abraira, Nico Döhler, Lucia Sinka, Francesco Brigo, Carla Bentes, and Johan Zelano have no conflicts of interest that are directly relevant to the content of this article.
Ethics approval Not applicable.

Consent to participate Not applicable.

Consent for publication Not applicable.

Availability of data and material Not applicable.

Code availability Not applicable.

Author contributions All authors contributed sections to the first draft of the manuscript. MG combined the sections to a first draft. All authors revised the manuscript draft for intellectual content and read and approved the final version.

Open Access This article is licensed under a Creative Commons Attribution-NonCommercial 4.0 International License, which permits any non-commercial use, sharing, adaptation, distribution and reproduction in any medium or format, as long as you give appropriate credit to the original author(s) and the source, provide a link to the Creative Commons licence, and indicate if changes were made. The images or other third party material in this article are included in the article's Creative Commons licence, unless indicated otherwise in a credit line to the material. If material is not included in the article's Creative Commons licence and your intended use is not permitted by statutory regulation or exceeds the permitted use, you will need to obtain permission directly from the copyright holder. To view a copy of this licence, visit http://creativecommons.org/licenses/by-nc/4.0/.

\section{References}

1. Lühdorf K, Jensen LK, Plesner AM. Etiology of seizures in the elderly. Epilepsia. 1986;27:458-63.

2. Seshadri S, Wolf PA. Lifetime risk of stroke and dementia: current concepts, and estimates from the Framingham Study. Lancet Neurol. 2007;6:1106-14.

3. Brondani R, de Almeida AG, Cherubini PA, Secchi TL, de Oliveira MA, Martins SCO, et al. Risk factors for epilepsy after thrombolysis for ischemic stroke: a cohort study. Front Neurol. 2020;10:1256.

4. Jung S, Schindler K, Findling O, Mono ML, Fischer U, Gralla $\mathrm{J}$, et al. Adverse effect of early epileptic seizures in patients receiving endovascular therapy for acute stroke. Stroke. 2012;43:1584-90.

5. Scoppettuolo P, Gaspard N, Depondt C, Legros B, Ligot N, Naeije G. Epileptic activity in neurological deterioration after ischemic stroke, a continuous EEG study. Clin Neurophysiol. 2019;130:2282-6.

6. Baranowski CJ. The quality of life of older adults with epilepsy: a systematic review. Seizure. 2018;60:190-7.

7. Verducci C, Hussain F, Donner E, Moseley BD, Buchhalter J, Hesdorffer D, et al. SUDEP in the North American SUDEP Registry: The full spectrum of epilepsies. Neurology. 2019;93:E227-36.

8. Beghi E, Carpio A, Forsgren L, Hesdorffer DC, Malmgren K, Sander JW, et al. Recommendation for a definition of acute symptomatic seizure. Epilepsia. 2010;51:671-5.

9. Fisher RS, Acevedo C, Arzimanoglou A, Bogacz A, Cross JH, Elger CE, et al. ILAE official report: a practical clinical definition of epilepsy. Epilepsia. 2014;55:475-82. 
10. Hesdorffer DC, Benn EKT, Cascino GD, Hauser WA. Is a first acute symptomatic seizure epilepsy? Mortality and risk for recurrent seizure. Epilepsia Epilepsia. 2009;50:1102-8.

11. Béjot Y, Bailly H, Durier J, Giroud M. Epidemiology of stroke in Europe and trends for the 21st century. Press Medicale. 2016;45:e391-8.

12. Forsgren L, Beghi E, Õun A, Sillanpää M. The epidemiology of epilepsy in Europe-a systematic review. Eur J Neurol. 2005;12:245-53.

13. Graham NSN, Crichton S, Koutroumanidis M, Wolfe CDA, Rudd AG. Incidence and associations of poststroke epilepsy: the prospective South London Stroke Register. Stroke. 2013;44:605-11.

14. Zelano J. Poststroke epilepsy: update and future directions. Ther Adv Neurol Disord. 2016;9(5):424-35.

15. Bentes C, Peralta AR, Martins H, Casimiro C, Morgado C, Franco AC, et al. Seizures, electroencephalographic abnormalities, and outcome of ischemic stroke patients. Epilepsia Open. 2017;2:441-52

16. Zelano J, Redfors P, Åsberg S, Kumlien E. Association between poststroke epilepsy and death: a nationwide cohort study. Eur Stroke J. 2016;1:272-8.

17. Guo J, Li J, Zhou M, Qin F, Zhang S, Wu B, et al. Statin treatment reduces the risk of poststroke seizures. Neurology. 2015;85:701-7.

18. Beghi E, D’Alessandro R, Beretta S, Consoli D, Crespi V, Delaj $\mathrm{L}$, et al. Incidence and predictors of acute symptomatic seizures after stroke. Neurology. 2011;77(20):1785-93.

19. Galovic M, Dohler N, Erdelyi-Canavese B, Felbecker A, Siebel $\mathrm{P}$, Conrad J, et al. Prediction of late seizures after ischaemic stroke with a novel prognostic model (the SeLECT score): a multivariable prediction model development and validation study. Lancet Neurol. 2018;17:143-52.

20. Pitkänen A, Roivainen R, Lukasiuk K. Development of epilepsy after ischaemic stroke. Lancet Neurol. 2016;15(2):185-97.

21. Bentes C, Brigo F, Zelano J, Ferro JM. Reperfusion therapies and poststroke seizures. Epilepsy Behav. 2020;104:106524.

22. Brigo F, Schneider M, Wagenpfeil G, Ragoschke-Schumm A, Fousse M, Holzhoffer C, et al. Intravenous thrombolysis with tPA and cortical involvement increase the risk of early poststroke seizures: results of a case-control study. Epilepsy Behav. 2020;104:106312.

23. Naylor J, Thevathasan A, Churilov L, Guo R, Xiong Y, Koome $\mathrm{M}$, et al. Association between different acute stroke therapies and development of post stroke seizures. BMC Neurol. 2018;18:1-7.

24. Belcastro V, Brigo F, Ferlazzo E, Gasparini S, Mastroianni G, Cianci V, et al. Incidence of early poststroke seizures during reperfusion therapies in patients with acute ischemic stroke: An observational prospective study: (TESI study: "Trombolisi/ Trombectomia e crisi Epilettiche precoci nello Stroke Ischemico"). Epilepsy Behav. 2019;104:106476.

25. Zöllner JP, Misselwitz B, Mauroschat T, Roth C, Steinmetz $\mathrm{H}$, Rosenow $\mathrm{F}$, et al. Intravenous thrombolysis or mechanical thrombectomy do not increase risk of acute symptomatic seizures in patients with ischemic stroke. Sci Rep Nat Res. 2020;10:1-7.

26. Ferlazzo E, Gasparini S, Beghi E, Sueri C, Russo E, Leo A, et al. Epilepsy in cerebrovascular diseases: review of experimental and clinical data with meta-analysis of risk factors. Epilepsia. 2016;57:1205-14.

27. Bentes C, Pimentel J, Ferro JM. Epileptic seizures following subcortical infarcts. Cerebrovasc Dis. 2001;12:331-4.

28. So EL, Annegers JF, Hauser WA, O’Brien PC, Whisnant JP. Population-based study of seizure disorders after cerebral infarction. Neurology. 1996;46:350-5.

29. Okuda S, Takano S, Ueno M, Hamaguchi H, Kanda F. Clinical features of late-onset poststroke seizures. J Stroke Cerebrovasc Dis. 2012;21:583-6.
30. Bladin CF, Alexandrov AV, Bellavance A, Bornstein N, Chambers B, Coté R, et al. Seizures after stroke: a prospective multicenter study. Arch Neurol. 2000;57:1617-22.

31. Wagner F, Erdelyi B, Siebel P, Weber J, Tettenborn B, Felbecker A. Post-stroke epilepsy: Does stroke volume matter? Eur J Neurol. 2011;18(Suppl. 2):20-65.

32. Haapaniemi E, Strbian D, Rossi C, Putaala J, Sipi T, Mustanoja $\mathrm{S}$, et al. The CAVE score for predicting late seizures after intracerebral hemorrhage. Stroke. 2014;45:1971-6.

33. Klein P, Dingledine R, Aronica E, Bernard C, Blümcke I, Boison D, et al. Commonalities in epileptogenic processes from different acute brain insults: do they translate? Epilepsia. 2018;59(1):37-66.

34. Klein P, Friedman A, Hameed MQ, Kaminski RM, Bar-Klein G, Klitgaard H, et al. Repurposed molecules for antiepileptogenesis: missing an opportunity to prevent epilepsy? Epilepsia. 2020;61:359-86.

35. Engel JJ, Pitkanen A, Loeb JA, Dudek FE, Bertram EH III, Cole AJ, et al. Epilepsy biomarkers. Epilepsia. 2013;54(Suppl 4):61-9.

36. Staba RJ, Stead M, Worrell GA. Electrophysiological biomarkers of epilepsy. Neurotherapeutics. 2014;11:334-46.

37. Bentes C, Rodrigues FB, Sousa D, Duarte GS, Franco AC, Marques R, et al. Frequency of post-stroke electroencephalographic epileptiform activity-a systematic review and metaanalysis of observational studies. Eur Stroke J. 2017;2:361-8.

38. Young GB, Jordan KG, Doig GS. An assessment of nonconvulsive seizures in the intensive care unit using continuous EEG monitoring: an investigation of variables associated with mortality. Neurology. 1996;47:83-9.

39. Beniczky S, Hirsch LJ, Kaplan PW, Pressler R, Bauer G, Aurlien $\mathrm{H}$, et al. Unified EEG terminology and criteria for nonconvulsive status epilepticus. Epilepsia. 2013;54:28-9.

40. Leitinger M, Beniczky S, Rohracher A, Gardella E, Kalss G, Qerama E, et al. Salzburg consensus criteria for non-convulsive status epilepticus-approach to clinical application. Epilepsy Behav. 2015;49:158-63.

41. Carrera E, Michel P, Despland PA, Maeder-Ingvar M, Ruffieux C, Debatisse D, et al. Continuous assessment of electrical epileptic activity in acute stroke. Neurology. 2006;67:99-104.

42. Jordan KG. Emergency EEG and continuous EEG monitoring in acute ischemic stroke. J Clin Neurophysiol. 2004;21:341-52.

43. Claassen J, Vespa P, Le Roux P, Menon DK, Citerio G, Bader $\mathrm{MK}$, et al. Electrophysiologic monitoring in acute brain injury. Neurocrit Care. 2014;21:129-47.

44. Claassen J, Mayer SA, Kowalski RG, Emerson RG, Hirsch LJ. Detection of electrographic seizures with continuous EEG monitoring in critically ill patients. Neurology. 2004;62:1743-8.

45. Kitchener N. Non-Convulsive Status Epilepticus in Ischemic Stroke and its Impact on Prognosis. Arch Neurol Neurosci. 2018;1:1-4.

46. Belcastro V, Vidale S, Gorgone G, Pisani LR, Sironi L, Arnaboldi $\mathrm{M}$, et al. Non-convulsive status epilepticus after ischemic stroke: a hospital-based stroke cohort study. J Neurol. 2014;261:2136-42.

47. Bentes C, Martins H, Peralta AR, Casimiro C, Morgado C, Franco AC, et al. Post-stroke seizures are clinically underestimated. J Neurol. 2017;264:1978-85.

48. Bentes C, Franco AC, Peralta AR, Viana P, Martins H, Morgado $\mathrm{C}$, et al. Epilepsia partialis continua after an anterior circulation ischaemic stroke. Eur J Neurol. 2017;24:929-34.

49. Bentes C, Martins H, Peralta AR, Morgado C, Casimiro C, Franco AC, et al. Early EEG predicts poststroke epilepsy. Epilepsia Open. 2018;3:203-12. 
50. Fonseca AC, Canhão P. Diagnostic difficulties in the classification of transient neurological attacks. Eur J Neurol. 2011;18:644-8.

51. Bentes C, Canhão P, Peralta AR, Viana P, Fonseca AC, Geraldes R, et al. Usefulness of EEG for the differential diagnosis of possible transient ischemic attack. Clin Neurophysiol Pract. 2018;3:11-9.

52. De Reuck J, Van Maele G. Transient ischemic attacks and inhibitory seizures in elderly patients. Eur Neurol. 2009;62:344-8.

53. Vezzani A, Balosso S, Ravizza T. Neuroinflammatory pathways as treatment targets and biomarkers in epilepsy. Nat Rev Neurol. 2019;15:459-72.

54. Bustamante A, López-Cancio E, Pich S, Penalba A, Giralt D, García-Berrocoso T, et al. Blood biomarkers for the early diagnosis of stroke: the stroke-chip study. Stroke. 2017;48:2419-25.

55. Bustamante A, Simats A, Vilar-Bergua A, García-Berrocoso T, Montaner J. Blood/brain biomarkers of inflammation after stroke and their association with outcome: from C-reactive protein to damage-associated molecular patterns. Neurotherapeutics. 2016;13:671-84.

56. Abraira L, Giannini N, Santamarina E, Cazorla S, Bustamante A, Quintana M, et al. Correlation of blood biomarkers with early-onset seizures after an acute stroke event. Epilepsy Behav. 2020;104:106549.

57. Rønn LCB, Hartz BP, Bock E. The neural cell adhesion molecule (NCAM) in development and plasticity of the nervous system. Exp Gerontol. 1998;33:853-64.

58. Dey A, Kang X, Qiu J, Du Y, Jiang J. Anti-inflammatory small molecules to treat seizures and epilepsy: from bench to bedside. Trends Pharmacol Sci. 2016;37:463-84.

59. Abraira L, Santamarina E, Cazorla S, Bustamante A, Quintana $\mathrm{M}$, Toledo M, et al. Blood biomarkers predictive of epilepsy after an acute stroke event. Epilepsia 2020;61:2244-53.

60. Eriksson H, Löwhagen Hendén P, Rentzos A, Pujol-Calderón F, Karlsson JE, Höglund K, et al. Acute symptomatic seizures and epilepsy after mechanical thrombectomy. Epilepsy Behav. 2020;104:106520.

61. Wu H, Brown EV, Acharya NK, Appelt DM, Marks A, Nagele RG, et al. Age-dependent increase of blood-brain barrier permeability and neuron-binding autoantibodies in S100B knockout mice. Brain Res. 2016;1637:154-67.

62. Al Ahmad A, Lee B, Stack J, Parham C, Campbell J, Clarke D, et al. Endostatin binds nerve growth factor and thereby inhibits neurite outgrowth and neuronal migration in-vitro. Brain Res. 2010;1360:28-39.

63. Eriksson H, Wirdefeldt K, Åsberg S, Zelano J. Family history increases the risk of late seizures after stroke. Neurology. 2019;93(21):e1964-70.

64. Yang H, Song Z, Yang GP, Zhang BK, Chen M, Wu T, et al. The ALDH2 rs671 polymorphism affects post-stroke epilepsy susceptibility and plasma 4-HNE levels. PLoS One. 2019;9(10):e109634.

65. Zhang B, Wu T, Song C, Chen M, Li H, Guo R. Association of CD40-1C/T polymorphism with cerebral infarction susceptibility and its effect on sCD40L in Chinese population. Int Immunopharmacol. 2013;16(4):461-5.

66. Fu CY, Chen SJ, Cai NH, Liu ZH, Zhang M, Wang PC, et al. Increased risk of post-stroke epilepsy in Chinese patients with a TRPM6 polymorphism. Neurol Res. 2019;41:378-83.

67. Tanaka T, Ihara M. Post-stroke epilepsy. Neurochem Int. 2017;107:219-28.

68. Huang CW, Saposnik G, Fang J, Steven DA, Burneo JG. Influence of seizures on stroke outcomes: a large multicenter study. Neurology. 2014;82:768-76.
69. Roivainen R, Haapaniemi E, Putaala J, Kaste M, Tatlisumak T. Young adult ischaemic stroke related acute symptomatic and late seizures: Risk factors. Eur J Neurol. 2013;20:1247-55.

70. Benninger F, Holtkamp M. Epileptic seizures and epilepsy after a stroke: Incidence, prevention and treatment. Nervenarzt. 2017;88:1197-207.

71. Witsch J, Frey HP, Schmidt JM, Velazquez A, Falo CM, Reznik $\mathrm{M}$, et al. Electroencephalographic periodic discharges and frequency-dependent brain tissue hypoxia in acute brain injury. JAMA Neurol American Medical Association. 2017;74:301-9.

72. Vespa P, Tubi M, Claassen J, Buitrago-Blanco M, McArthur D, Velazquez AG, et al. Metabolic crisis occurs with seizures and periodic discharges after brain trauma. Ann Neurol. 2016;79:579-90.

73. Holtkamp M, Beghi E, Benninger F, Kälviäinen R, Rocamora R, Christensen H. European Stroke Organisation guidelines for the management of post-stroke seizures and epilepsy. Eur Stroke J. 2017;2:103-15.

74. Pitkänen A, Lukasiuk K, Dudek FE, Staley KJ. Epileptogenesis. Csh Perspect Med. 5:a022822.

75. Trinka E, Brigo F. Antiepileptogenesis in humans: disappointing clinical evidence and ways to move forward. Curr Opin Neurol. 2014;27(2):227-35.

76. Van Tuijl JH, Van Raak EPM, De Krom MCTFM, Lodder J, Aldenkamp AP. Early treatment after stroke for the prevention of late epileptic seizures: a report on the problems performing a randomised placebo-controlled double-blind trial aimed at anti-epileptogenesis. Seizure 2011;20:285-91.

77. Doeser A, Dickhof G, Reitze M, Uebachs M, Schaub C, Pires NM, et al. Targeting pharmacoresistant epilepsy and epileptogenesis with a dual-purpose antiepileptic drug. Brain. 2015;138:371-87.

78. Liu SJ, Zheng P, Wright DK, Dezsi G, Braine E, Nguyen T, et al. Sodium selenate retards epileptogenesis in acquired epilepsy models reversing changes in protein phosphatase $2 \mathrm{~A}$ and hyperphosphorylated tau. Brain. 2016;139:1919-38.

79. Li Y, Zhang B, Zhang L, Xie D, Li Y. Efficacy of Statin therapy in post-stroke seizure prophylaxis: clues from an observational study of routine secondary prevention treatment. Seizure. 2019;71:185-9.

80. Vitturi BK, Gagliardi RJ. The influence of statins on the risk of post-stroke epilepsy. Neurol Sci. 2020;41:1851-7.

81. Hanlon JT. Drug-related problems updates. Am J Geriatr Pharmacother. 2004;2:88-90.

82. Siebenbrodt K, Strzelczyk A, Rosenow F. Epilepsy in old age. Nervenarzt. 2020;91:353-61.

83. Price M, Günther A, Kwan JSK. Antiepileptic drugs for the primary and secondary prevention of seizures after intracranial venous thrombosis. Cochrane Database Syst Rev. 2014;8:1465-858.

84. Brigo F, Lattanzi S, Zelano J, Bragazzi NL, Belcastro V, Nardone $\mathrm{R}$, et al. Randomized controlled trials of antiepileptic drugs for the treatment of post-stroke seizures: a systematic review with network meta-analysis. Seizure. 2018;61:57-62.

85. Gilad R, Sadeh M, Rapoport A, Dabby R, Boaz M, Lampl Y. Monotherapy of lamotrigine versus carbamazepine in patients with poststroke seizure. Clin Neuropharmacol. 2007;30:189-95.

86. Consoli D, Bosco D, Postorino P, Galati F, Plastino M, Perticoni $\mathrm{GF}$, et al. Levetiracetam versus carbamazepine in patients with late poststroke seizures: A multicenter prospective randomized open-label study (Epic Project). Cerebrovasc Dis Karger Publishers. 2012;34:282-9.

87. Sales F, Chaves J, McMurray R, Loureiro R, Fernandes H, Villanueva V. Eslicarbazepine acetate in post-stroke epilepsy: Clinical practice evidence from Euro-Esli. Scand: Acta Neurol; 2020. 
88. Alvarez-Sabín J, Montaner J, Padró L, Molina CA, Rovira R, Codina A, et al. Gabapentin in late-onset poststroke seizures. Neurology. 2002;59:1991-3.

89. Belcastro V, Costa C, Galletti F, Autuori A, Pierguidi L, Pisani $\mathrm{F}$, et al. Levetiracetam in newly diagnosed late-onset post-stroke seizures: a prospective observational study. Epilepsy Res. 2008;82:223-6.

90. Kutlu G, Gomceli YB, Unal Y, Inan LE. Levetiracetam monotherapy for late poststroke seizures in the elderly. Epilepsy Behav. 2008;13:542-4.

91. Huang YH, Chi NF, Kuan YC, Chan L, Hu CJ, Chiou HY, et al. Efficacy of phenytoin, valproic acid, carbamazepine and new antiepileptic drugs on control of late-onset post-stroke epilepsy in Taiwan. Eur J Neurol. 2015;22:1459-68.

92. Rowan AJ, Ramsay RE, Collins JF, Pryor F, Boardman KD, Uthman BM, et al. New onset geriatric epilepsy: a randomized study of gabapentin, lamotrigine, and carbamazepine. Neurology. 2005;64:1868-73.

93. Baulac M, Rosenow F, Toledo M, Terada K, Li T, De Backer M, et al. Efficacy, safety, and tolerability of lacosamide monotherapy versus controlled-release carbamazepine in patients with newly diagnosed epilepsy: a phase 3, randomised, double-blind, noninferiority trial. Lancet Neurol. 2017;16:43.

94. Brodie MJ, Overstall PW, Giorgi L. Multicentre, double-blind, randomised comparison between lamotrigine and carbamazepine in elderly patients with newly diagnosed epilepsy. Epilepsy Res. 1999;37:81-7.

95. Saetre E, Perucca E, Isojärvi J, Gjerstad L, Babic T, Hodoba $\mathrm{D}$, et al. An international multicenter randomized double-blind controlled trial of lamotrigine and sustained-release carbamazepine in the treatment of newly diagnosed epilepsy in the elderly. Epilepsia. 2007;48:1292-302.

96. Werhahn KJ, Trinka E, Dobesberger J, Unterberger I, Baum P, Deckert-Schmitz M, et al. A randomized, double-blind comparison of antiepileptic drug treatment in the elderly with new-onset focal epilepsy. Epilepsia. 2015;56:450-9.

97. Pohlmann-Eden B, Marson AG, Noack-Rink M, Ramirez F, Tofighy A, Werhahn KJ, et al. Comparative effectiveness of levetiracetam, valproate and carbamazepine among elderly patients with newly diagnosed epilepsy: subgroup analysis of the randomized, unblinded KOMET study. BMC Neurol. 2016;16(1):1-2.

98. Lattanzi S, Zaccara G, Giovannelli F, Grillo E, Nardone R, Silvestrini $\mathrm{M}$, et al. Antiepileptic monotherapy in newly diagnosed focal epilepsy. A network meta-analysis. Acta Neurol Scand. 2019;139:33-41.

99. Rosenow F, Brandt C, Bozorg A, Dimova S, Steiniger-Brach B, Zhang Y, et al. Lacosamide in patients with epilepsy of cerebrovascular etiology. Acta Neurol Scand. 2020;141:473-82.

100. Belcastro V, Vidale S, Pierguidi L, Sironi L, Tancredi L, Striano $\mathrm{P}$, et al. Intravenous lacosamide as treatment option in post-stroke non convulsive status epilepticus in the elderly: a proof-of-concept, observational study. Seizure. 2013;22:905-7.

101. Zelano J, Holtkamp M, Agarwal N, Lattanzi S, Trinka E, Brigo F. How to diagnose and treat post-stroke seizures and epilepsy. Epileptic Disord. 2020;22:252-63.

102. LoPinto-Khoury C, Mintzer S. Antiepileptic drugs and markers of vascular risk. Curr Treat Opt Neurol. 2010;12:300-8.

103. Katsiki N, Mikhailidis DP, Nair DR. The effects of antiepileptic drugs on vascular risk factors: a narrative review. Seizure. 2014;23:677-84.

104. Popova LV, Kondratieva TB, Aksenova MB, Khlevchuk TV, Kanevskaya MZ. Recommendations on the use of non-vitamin $\mathrm{K}$ antagonist oral anticoagulants in patients with atrial fibrillation (based on 2018 European Heart Rhythm Association Practical Guide). Kardiologiia. 2019;59:68-79.
105. Stöllberger C, Finsterer J. Interactions between non-vitamin $\mathrm{K}$ oral anticoagulants and antiepileptic drugs. Epilepsy Res. 2016;126:98-101.

106. Von Oertzen TJ, Trinka E, Bornstein NM. Levetiracetam and non-Vitamin $\mathrm{K}$ antagonist oral anticoagulants in patients with atrial fibrillation and epilepsy: a reasonable combination. Eur Heart J. 2019;40:3800-1.

107. Brodie MJ, Kwan P. Epilepsy in elderly people. Br Med J. 2005;331:1317-22.

108. St. Louis E. Minimizing AED adverse effects: improving quality of life in the interictal state in epilepsy care. Curr Neuropharmacol. 2009;7:106-14.

109. Jankovic SM, Dostic M. Choice of antiepileptic drugs for the elderly: possible drug interactions and adverse effects. Expert Opin Drug Metab Toxicol. 2012;8:81-91.

110. Park SP, Kwon SH. Cognitive effects of antiepileptic drugs. J Clin Neurol. 2008;4:99-106.

111. Lee HW, Jung DK, Suh CK, Kwon SH, Park SP. Cognitive effects of low-dose topiramate monotherapy in epilepsy patients: a 1-year follow-up. Epilepsy Behav. 2006;8:736-41.

112. Meador KJ, Gevins A, Loring DW, McEvoy LK, Ray PG, Smith ME, et al. Neuropsychological and neurophysiologic effects of carbamazepine and levetiracetam. Neurology. 2007;69:2076-84.

113. Magalhães JC, Gongora M, Vicente R, Bittencourt J, Tanaka G, Velasques B, et al. The influence of Levetiracetam in cognitive performance in healthy individuals: neuropsychological, behavioral and electrophysiological approach. Clin Psychopharmacol Neurosci. 2015;13:83-93.

114. Caplan R, Siddarth P, Stahl L, Lanphier E, Vona P, Gurbani S, et al. Childhood absence epilepsy: Behavioral, cognitive, and linguistic comorbidities. Epilepsia. 2008;49:1838-46.

115. Hamed SA. Psychiatric symptomatologies and disorders related to epilepsy and antiepileptic medications. Expert Opin Drug Saf. 2011;10:913-34.

116. Chen B, Choi H, Hirsch LJ, Katz A, Legge A, Buchsbaum R, et al. Psychiatric and behavioral side effects of antiepileptic drugs in adults with epilepsy. Epilepsy Behav. 2017;76:24-31.

117. Ruiz-Giménez J, Sánchez-Álvarez JC, Cañadillas-Hidalgo F, Serrano-Castro PJ. Antiepileptic treatment in patients with epilepsy and other comorbidities. Seizure. 2010;19:375-82.

118. Pack AM. Treatment of epilepsy to optimize bone health. Curr Treat Opt Neurol. 2011;13:346-54.

119. Perucca E, Berlowitz D, Birnbaum A, Cloyd JC, Garrard J, Hanlon JT, et al. Pharmacological and clinical aspects of antiepileptic drug use in the elderly. Epilepsy Res. 2006;68:49-63.

120. Watkins L, O'Dwyer M, Shankar R. New anti-seizure medication for elderly epileptic patients. Expert Opin Pharmacother. 2019;20:1601-8.

121. Zhong R, Chen Q, Zhang X, Li M, Liang J, Lin W. Bone mineral density loss in people with epilepsy taking valproate as a monotherapy: a systematic review and meta-analysis. Front Neurol. 2019;10:1-8

122. Souverein PC, Webb DJ, Weil JG, Van Staa TP, Egberts ACG. Use of antiepileptic drugs and risk of fractures: casecontrol study among patients with epilepsy. Neurology. 2006;66:1318-24.

123. Ranta A, Wooten GF. Hyponatremia due to an additive effect of carbamazepine and thiazide diuretics. Epilepsia. 2004;45:879.

124. Wechsler RT, Radtke RA, Smith M, Vossler DG, Strom L, Trinka $\mathrm{E}$, et al. Serum sodium levels and related treatment-emergent adverse events during eslicarbazepine acetate use in adults with epilepsy. Epilepsia. 2019;60:1341-52.

125. Galgani A, Palleria C, Iannone LF, De Sarro G, Giorgi FS, Maschio M, et al. Pharmacokinetic interactions of clinical interest between direct oral anticoagulants and antiepileptic drugs. Front Neurol. 2018;9:1067 
126. Gidal BE, French JA, Grossman P, Le Teuff G. Assessment of potential drug interactions in patients with epilepsy: impact of age and sex. Neurology. 2009;72:419-25.

127. Mintzer S, Maio V, Foley K. Use of antiepileptic drugs and lipid-lowering agents in the United States. Epilepsy Behav. 2014;34:105-8.

128. Faught E, Szaflarski JP, Richman J, Funkhouser E, Martin RC, Piper K, et al. Risk of pharmacokinetic interactions between antiepileptic and other drugs in older persons and factors associated with risk. Epilepsia. 2018;59:715-23.

129. Camilo O, Goldstein LB. Seizures and epilepsy after ischemic stroke. Stroke. 2004;35(7):1769-75.

130. De Kinderen RJA, Evers SMAA, Rinkens R, Postulart D, Vader CI, Majoie MHJM, et al. Side-effects of antiepileptic drugs: the economic burden. Seizure Eur J Epilepsy. 2014;23:184-90.

131. Guekht AB. Withdrawal of antiepileptic drugs in seizurefree patients: chance or jeopardy? Nat Clin Pract Neurol. 2008;4:598-9.

132. Lossius MI, Hessen E, Mowinckel P, Stavem K, Erikssen J, Gulbrandsen $\mathrm{P}$, et al. Consequences of antiepileptic drug withdrawal: a randomized, double-blind study (Akershus Study). Epilepsia. 2008;49:455-63.

133. Lamberink HJ, Otte WM, Geerts AT, Pavlovic M, RamosLizana J, Marson AG, et al. Individualised prediction model of seizure recurrence and long-term outcomes after withdrawal of antiepileptic drugs in seizure-free patients: a systematic review and individual participant data meta-analysis. Lancet Neurol. 2017;16:523-31.

134. Strozzi ISJ. Early versus late antiepileptic drug withdrawal for people with epilepsy in remission. Cochrane Database Syst Rev. 2015;2:1465-858.
135. Zelano J, Lundberg RG, Baars L, Hedegärd E, Kumlien E. Clinical course of poststroke epilepsy: a retrospective nested casecontrol study. Brain Behav. 2015;5(9):e00366.

136. Arntz RM, Maaijwee NAM, Rutten-Jacobs LCA, Schoonderwaldt HC, Dorresteijn LD, Van Dijk EJ, et al. Epilepsy after TIA or stroke in young patients impairs long-term functional outcome the future study. Neurology. 2013;81:1907-13.

137. Kumral E, Uncu G, Dönmez I, Cerrahoglu Şirin T, Alpaydn S, Çall C, et al. Impact of poststroke seizures on neurological deficits: Magnetic resonance diffusion-weighted imaging study. Eur Neurol. 2013;69:200-6.

138. Leung T, Leung H, Soo YOY, Mok VCT, Wong KS. The prognosis of acute symptomatic seizures after ischaemic stroke. J Neurol Neurosurg Psychiatry. 2017;88:86-94.

139. Gilad R, Lampl Y, Eschel Y, Sadeh M. Antiepileptic treatment in patients with early postischemic stroke seizures: a retrospective study. Cerebrovasc Dis. 2001;12:39-43.

140. Krumholz A, Wiebe S, Gronseth GS, Gloss DS, Sanchez AM, Kabir AA, Liferidge AT, Martello JP, Kanner AM, Shinnar S, Hopp JL. Evidence-based guideline: management of an unprovoked first seizure in adults: report of the guideline development subcommittee of the American academy of neurology and the american epilepsy society: evidence-based guideline. Epilepsy Curr. 2015;15(3):144-52.

141. van Tuijl JH, van Raak EPM, van Oostenbrugge RJ, Aldenkamp AP, Rouhl RPW. The occurrence of seizures after ischemic stroke does not influence long-term mortality; a 26-year follow-up study. J Neurol. 2018;265:1780-8. 